\title{
Retrospective Survey on the Prevalence and Outcome of Prior Autoimmune Diseases in Patients with Aplastic Anemia Reported to the Registry of the European Group for Blood and Marrow Transplantation
}

\author{
Simone Cesaro ${ }^{a}$ Judith Marsh ${ }^{b}$ Gloria Tridello $^{a} \quad$ Alicia Rovò $^{c}$ Sebastien Maury ${ }^{d}$ \\ Barbara Montante $^{\mathrm{e}}$ Tamás Masszi $^{\mathrm{f}}$ Maria Teresa Van Lint ${ }^{\mathrm{g}}$ Boris Afanasyev ${ }^{\mathrm{h}}$ \\ Arturo Iriondo Atienza ${ }^{i}$ Marc Bierings ${ }^{j} \quad$ Cecilia Carbone $^{k} \quad$ Michael Doubek $^{\prime}$ Edoardo Lanino $^{\mathrm{m}}$ \\ Mahmoud Sarhan $^{n}$ Antonio Risitano $^{\circ}$ Katerina Steinerova $^{p} \quad$ Anders Wahlin $^{q}$ \\ Anna Pegoraro ${ }^{a}$ Jakob Passweg ${ }^{r}$

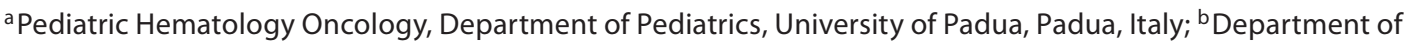

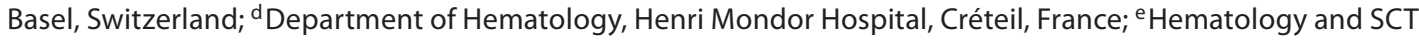

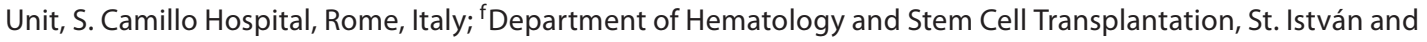
St. Laszlo Hospital, Budapest, Hungary; ${ }^{9}$ Department of Hematology II, Ospedale San Martino, Genoa, Italy; hDepartment of Hematology and Transplantology, St. Petersburg State Medical Pavlov University, St. Petersburg, Russia; 'Department of Hematology, Marqués de Valdecilla University Hospital, Santander, Spain; jDepartment of Hematology, University Hospital for Children (WKZ), Utrecht, The Netherlands; ${ }^{k}$ Department of Hematology, Spedali Civili, Brescia, Italy; 'Department of Internal Medicine, Hematology and Oncology, University Hospital, Brno, Czech Republic; ${ }^{m}$ Department of Pediatric Hematology Oncology, G. Gaslini Institute, Genoa, Italy; ${ }^{\text {nKing }}$ Hussein Cancer Centre, Amman, Jordan; 'Division of Hematology, 'Federico II' Medical School, University of Naples, Naples, Italy; ${ }^{\circ}$ Department of Hematology/Oncology, Charles University Hospital, Pilsen, Czech Republic; ${ }^{9}$ Department of Hematology, Umea University Hospital, Umeå, Sweden; ' Department of Internal Medicine, University Hospital, Geneva, Switzerland
\end{abstract} \\ Haematological Medicine, King's College Hospital, London, UK; ' ${ }^{C}$ Department of Hematology, University Hospital,
}

\section{Key Words}

Aplastic anemia $\cdot$ Autoimmune disease $\cdot$ Hematopoietic stem cell transplantation $\cdot$ Immunosuppression

\begin{abstract}
Background: Aplastic anemia (AA) is rarely described after a diagnosis of autoimmune disease (aID). Aims: To assess the prevalence of prior aID in patients with AA recorded in the registry of the European Group for Blood and Marrow Transplantation (EBMT) and to evaluate treatment and outcome.
\end{abstract}

Methods: 1,251 AA patients from 18 EBMT centers were assessed. Results: Fifty patients (4\%) were eligible: 22 males and 28 females with a median age of 46 years at the diagnosis of aID and of 51 years at the diagnosis of AA. Information on the treatment of AA was available in 49 patients: 38 received only immunosuppressive therapy (IST), 8 patients underwent hematopoietic stem cell transplantation (HSCT) - 6 as first-line therapy and 2 after failure of IST - whilst 3 patients had a spontaneous recovery. After a median follow-up of 3.19 years, 32 patients were alive, including 7 of the 8 patients who underwent HSCT. Only 6 of 32 patients who were

\section{KARGER}

Fax +41613061234 E-Mail karger@karger.ch www.karger.com
(C) 2010 S. Karger AG, Base

$0001-5792 / 10 / 1241-0019 \$ 26.00 / 0$

Accessible online at:

www.karger.com/aha
Simone Cesaro, MD

Pediatric Hematology Oncology, Department of Pediatrics

Azienda Ospedaliera di Verona, P.le L.A. Scuro

IT-35174 Verona (Italy)

Tel. +39 045812 4931, Fax +39 049812 4909, E-Mail simone.cesaro@ azosp.vr.it 
alive at the last follow-up were receiving IST for AA. Conclusions: Most cases of AA following aID benefitted from IST or HSCT if a matched donor was available. Further prospective investigation is needed to assess the effects of IST on the outcome of underlying alD. Copyright $\odot 2010$ s. Karger AG, Basel

\section{Introduction}

Aplastic anemia (AA) is caused by an acquired $\mathrm{T}$ cell immune dysfunction that impairs bone marrow progenitor cell function. This results in progressive cytopenia and the need for red cell and platelet transfusion. Several factors have been advocated as a trigger for the development of AA (viral infections, drugs, chemical compounds and pregnancy), but recent data highlight the role of dysregulation of immune response and of cytotoxic $\mathrm{T}$ cells expressing Th1 cytokines as effector cells [1]. Some authors described the occurrence of AA in patients suffering from autoimmune diseases (aIDs), suggesting that AA may be caused by a common dysregulation of immune response in recognizing self-antigens [2-14]. Recently, Stalder et al. [15] found that 13 of 243 patients (5.3\%) had an aID before the diagnosis of AA and 11 of 243 patients (4.5\%) developed an aID after the diagnosis of and treatment for AA.

The primary aim of this study was to perform a retrospective survey of the prevalence of prior aID in patients with AA reported in the registry of the European Group for Blood and Marrow Transplantation (EBMT) and to evaluate their treatment and outcome.

\section{Patients and Methods}

The study was approved by the scientific committee of the EBMT-Severe Aplastic Anemia Working Party. Patients were eligible if they had a diagnosis of any aID before the occurrence of AA. EBMT participating centers were asked to fill in a case report form (MED C form) containing specific information which was not evaluable in the EBMT registry database, such as type of aID, date of diagnosis, response of the aID to AA treatment and current status. Data collection and processing were in accordance with EBMT guidelines asking for informed consent, and anonymized data-sharing with EBMT. Immunosuppressive therapy (IST) was performed according to EBMT guidelines for severe AA (SAA) [16].

The definition of AA and response to treatment were according to standard criteria [17]. Follow-up was up to December 31, 2008.

\section{Results}

Eighteen EBMT centers from 11 countries agreed to participate in the study, identifying 50 patients (Appendix 1). Considering the number of AA patients reported by those centers during the study period $(n=1,251)$, the prevalence was $4 \%$. Of these 50 patients, 22 were males and 28 were females with a median age of 46 years (range 9-75) at the diagnosis of aID and of 51 years (range 1277) at the diagnosis of AA.

The reported diagnosis of aIDs and numbers of affected patients were as follows: rheumatic arthritis in 12, psoriasis in 5 , scleroderma in 4 , ulcerative colitis in 4 , autoimmune hypothyroidism in 4 , ankylosing spondylitis in 3, multiple sclerosis in 3, systemic lupus erythematosus in 3, Sjögren's syndrome in 2, focal segmental glomerulosclerosis in 2, diabetes in 1 , dermatitis herpertiformis in 1 , pernicious anemia in 1 , myasthenia gravis in 1 , polyangiitis in 1 , primary antiphospholipid syndrome in 1 , celiac disease in 1 , and immune thrombocytopenic purpura in 1.

The center investigator judged that in 17 of 50 patients (34\%), the development of AA was possibly related to drugs administered to treat the aIDs, such as gold salts in 5, salazopyrine in 4 , azathioprine in 3 , and in 1 each for fenbufen, indomethacin, mesalazine, and carbamazepine.

AA was classified as nonsevere AA (NSAA) in 17 patients, SAA in 16 patients and very severe (VSAA) in 12 patients; for 5 patients, the data were not available.

Information on the treatment of A A was available in 49 of 50 patients: 38 received only 1-2 courses of IST, 8 patients underwent hematopoietic stem cell transplantation (HSCT) -6 as first-line therapy and 2 after failure of IST - whilst 3 patients had a spontaneous recovery. The underlying diseases in these patients were as follows: psoriasis in 3 , rheumatoid arthritis in 2, autoimmune hypothyroidism in 1 , scleroderma in 1 and diabetes type 1 in 1.

Table 1 summarizes the type and results of IST. Complete and partial response rates were 37.5 and $22.5 \%$, respectively. Given the different types of aID, the search for any potential correlation between the previous underlying disease and the response to IST was not possible.

In 26 of 38 patients treated with IST, the center investigator also recorded the effect of this therapy on the underlying aIDs. IST exerted a clinically beneficial effect on the aIDs in 11 patients; in 13 patients, no changes were observed whilst 2 patients experienced a worsening of their aIDs with their recovery from AA.

In the 8 HSCT patients, the donor was related in 6 cases ( 5 were siblings) and unrelated in the other 2 cases. 
Table 1. Results of IST in the 40 patients treated (including the 2 patients who failed IST before undergoing HSCT)

\begin{tabular}{|c|c|c|c|c|}
\hline Type of treatment & $\begin{array}{l}\text { Complete } \\
\text { response }\end{array}$ & $\begin{array}{l}\text { Partial } \\
\text { response }\end{array}$ & $\begin{array}{l}\text { No } \\
\text { response }\end{array}$ & $\begin{array}{l}\text { Data not } \\
\text { available }\end{array}$ \\
\hline ALS or $\mathrm{ATG}^{1}$ or alentuzumab & 3 & 1 & 5 & 1 \\
\hline CSA & & $1^{1}$ & 1 & \\
\hline ALS or ATG + CSA & 9 & 4 & 6 & \\
\hline ALS or ATG or CSA + another treatment ${ }^{2}$ & 3 & 2 & 2 & \\
\hline $\begin{array}{l}\text { Prednisone with azathioprine or } \\
\text { cyclophosphamide }\end{array}$ & & 1 & & 1 \\
\hline Total & $15(37.5 \%)$ & $9(22.5 \%)$ & $14(35 \%)$ & $2(5 \%)$ \\
\hline \multicolumn{5}{|c|}{$\begin{array}{l}\text { ALS = Antilymphocyte serum; ATG = antithymocyte serum; CSA = cyclosporine; } \\
\text { HSCT = hematopoietic stem cell transplantation. } \\
{ }^{1} \text { Coupled with plasma exchange. } \\
{ }^{2} \text { Other treatment: oxymetholone in } 3 \text {, granulocyte colony-stimulating factor in } 3 \text {, }\end{array}$} \\
\hline
\end{tabular}

These last 2 patients have previously failed the IST with cyclosporine and antithymocyte globulin (ATG) whilst the first 6 patients received the related allogeneic HSCT as first-line treatment of AA. The stem cell source was bone marrow and peripheral blood in 4 cases each. Seven patients received a nonmyeloablative conditioning regimen consisting of $120-200 \mathrm{mg} / \mathrm{kg}$ of cyclophosphamide \pm ATG or alemtuzumab. Total body irradiation was also attempted in 1 of them. One patient received a reducedintensity conditioning with cyclophosphamide-fludarabine and ATG.

Outcome: after a median follow-up of 3.19 years (range $0.2-17), 32$ patients were alive, including 7 of the 8 patients who underwent HSCT. Viral infection was the cause of death in the 8th HSCT patient.

Three patients were lost to follow-up. Overall, 15 patients died -6 of infections, 2 of chronic obstructive pulmonary disease, 2 of bleeding, and 5 of other unspecified causes. Only 6 of 32 patients who were alive at the last follow-up were receiving continued IST for AA, either with low doses of steroids or androgens.

\section{Discussion}

In this study, we found that $4 \%$ of patients recorded in the Aplastic Anemia Registry of EBMT had a prior aID. This figure confirms that published recently in the singlecenter study of Stalder et al. [15] in which $5.3 \%$ of patients with AA had been previously diagnosed and treated for AIDs. In that study, this association was more frequent in older patients. In line with that observation, the median age at diagnosis of aIDs was 46 years in our cohort and that of AA 51 years, i.e. a median of 5 years older.

Overall, the development of bone marrow failure is a not so rare complication in patients with aIDs, and it was found in both forms with B cell and T cell dysfunction. In contrast to the figures reported by Stalder et al. [15], female gender was more represented than male gender, as expected in aIDs. Moreover, previous or concurrent rheumatic aIDs were more frequently reported than other aIDs. In the investigator's opinion, this can, in part, be explained by the fact that in $34 \%$ of the cases, bone marrow failure was associated with previous treatment with drugs that are potentially toxic to marrow stem cells and are commonly used in the treatment of rheumatic arthritis. Nevertheless, in the absence of an adequate control group, we were not able to elucidate the pathogenic role of these therapies.

Irrespective of the type of aID and the pathogenesis of bone marrow dysfunction, a complete or partial response was obtained with IST in more than half of the patients, and of note, without a rebound of the aID following IST withdrawal, except in 2 cases. In addition, almost one third of the patients (11/38) reduced their treatments for their aIDs after IST for AA.

The type of IST varied among patients, but the most successful combination was based on ATG and cyclosporine: 13 of 19 patients treated (68\%) obtained complete or partial responses. Nowadays, this combination is considered the standard of care also for all the forms of autoimmune/idiopathic bone marrow deficiency (AA, SAA, and VSAA) not associated with aIDs. It has been speculated that a common cytokine pathway such as that mediated 
by interferon- $\gamma$ secretion may play a role in apparently unrelated diseases, such as AA and several aIDs [6].

Interestingly, there were no cases of graft failure following HSCT or uncommon transplantation-related mortality; in all cases but 1, HSCT resulted in cure [9], but we acknowledge that no major conclusions can be drawn due to the limited number of patients.

In conclusion, in most cases, all the forms of bone marrow failure - AA, SAA, and VSAA - following aIDs deserve a standard approach with IST using the combination of ATG plus cyclosporine, or consideration for allogeneic HSCT if a sibling-matched donor is available, and the patient has SAA. These forms of bone marrow failure respond to IST although the pathogenic mechanism is not completely elucidated. Considering the limited data available and the heterogeneity of IST drugs available, a prospective study is needed to assess the effects of IST on the final outcome of specific aIDs.

\section{Acknowledgements}

We thank Rosi Oneto for her collaboration in collecting and analyzing the data and Mr. Rodney Seddom for reviewing the English.

\section{Appendix 1}

\begin{tabular}{|c|c|c|c|c|}
\hline Investigator & $\mathrm{CIC}$ & State & Center & $\begin{array}{l}\text { Patients } \\
\mathrm{n}\end{array}$ \\
\hline Judith Marsh & 539 & UK & London & 23 \\
\hline Alicia Rovò & 202 & Switzerland & Basel & 6 \\
\hline Simone Cesaro & 285 & Italy & Padua & 2 \\
\hline Sebastien Maury & 252 & France & Paris & 2 \\
\hline Barbara Montante & 287 & Italy & Rome & 2 \\
\hline \multicolumn{5}{|l|}{ Maria Teresa Van } \\
\hline Lint & 217 & Italy & Genoa & 2 \\
\hline Tamás Masszi & 556 & Hungary & Budapest & 2 \\
\hline Boris Afanasyev & 725 & Russia & St. Petersburg & 1 \\
\hline \multicolumn{5}{|l|}{ Arturo Iriondo } \\
\hline Atienza & 242 & Spain & Santander & 1 \\
\hline Marc Bierings & 239 & The Netherlands & Utrecht & 1 \\
\hline Cecilia Carbone & 288 & Italy & Brescia & 1 \\
\hline Michael Doubek & 597 & Czech Republic & Brno & 1 \\
\hline Edoardo Lanino & 274 & Italy & Genoa & 1 \\
\hline Jakob Passweg & 261 & Switzerland & Geneva & 1 \\
\hline Mahmoud Sarhan & 580 & Jordan & Amman & 1 \\
\hline Antonio Risitano & 766 & Italy & Naples & 1 \\
\hline Katerina Steinerova & 718 & Czech Republic & Pilsen & 1 \\
\hline Anders Wahlin & 731 & Sweden & Umeå & 1 \\
\hline
\end{tabular}

$\mathrm{CIC}=\mathrm{EBMT}$ center identification code.

\section{References}

1 Young NS, Calado RT, Scheinberg P: Current concepts in the pathophysiology and treatment of aplastic anemia. Blood 2006; 108: 2509-2519.

-2 Cavalcant J, Shadduck RK, Winkelstein A, Zeigler Z, Mendelow H: Red-cell hypoplasia and increased bone marrow reticulin in systemic lupus erythematosus: reversal with corticosteroid therapy. Am J Hematol 1978; 5:253-263.

-3 Stricker RB, Shuman MA: Aplastic anemia complicating systemic lupus erythematosus: response to androgens in two patients. Am J Hematol 1984;17:193-201.

-4 Bailey FA, Lilly M, Bertoli LF, Ball GV: An antibody that inhibits in vitro bone marrow proliferation in a patient with systemic lupus erythematosus and aplastic anemia. Arthritis Rheum 1989;32:901-905.

5 Sumimoto S, Kawai M, Kasajima Y, Hamamoto T: Aplastic anemia associated with systemic lupus erythematosus. Am J Hematol 1991;38:329-331.

-6 Hinterberger-Fischer M, Kier P, Forstinger I, Lechner K, Kornek G, Breyer S, Ogris H, Pont J, Hinterberger W: Coincidence of severe aplastic anemia with multiple sclerosis or thyroid disorders. Report of 5 cases. Acta Haematol 1994;92:136-139.
-7 Satoh M, Yamagata H, Watanabe F, Matsushita Y, Nakayama S, Murakami M, Matsuyama J, Oshima S, Akizuki M: A case of Sjögren's syndrome complicating immunemediated aplastic anemia. Clin Rheumatol 1993;12:257-260.

8 Matsumoto N, Kagawa H, Ichiyoshi H, Iguchi T, Yamanaka Y, Kishimoto Y, Fukuhara S: Aplastic anemia complicating Sjögren's syndrome. Intern Med 1997;36:371-374.

$\checkmark 9$ Diez S, Banias H, Diez-Martin JL, Briz M, Estrado J, Barcelò B: Apparent cure of Graves-Basedow disease after sibling allogeneic bone marrow transplantation. Clin Endocrinol 1999;50:267-270.

10 Tomonari A, Tojo A, Iseki T, Ooi J, Hase H, Shirafuji N, Tani K, Asano S: Severe aplastic anemia with autoimmune thyroiditis showing no hematological response to intensive immunosuppressive therapy. Acta Haematol 2003;109:90-94.

$\checkmark 11$ Lee WY, Oh ES, Min CK, Kim DW, Lee JW, Kang MI, Min WS, Cha BY, Lee KW, Son HY, Kang SK, Kim CC: Changes in autoimmune thyroid disease following allogeneic bone marrow transplantation. Bone Marrow Transplant 2001;28:63-66.
12 Kumar M, Goldman J: Severe aplastic anaemia and Grave's disease in a paediatric patient. Br J Haematol 2002;118:327-329.

13 Singh NP, Prakash A, Garg D, Makhija A, Pathania A, Prakash N, Kubba S, Agarwal SK: Aplastic anemia complicating systemic lupus erythematosus: successful management with cyclosporine. Rheumatol Int 2004;24:40-42.

14 Grey-Davies E, Hows JM, Marsh JC: Aplastic anaemia in association with coeliac disease: a series of three cases. Br J Haematol 2008; 143:258-260.

15 Stalder MP, Rovò A, Halter J, Heim D, Silzle T, Passweg J, Rischewski J, Stern M, Arber C, Buser A, Meyer-Monard S, Tichelli A, Gratwohl A: Aplastic anemia and concomitant autoimmune diseases. Ann Hematol 2009; 88:659-665.

16 Bacigalupo A: Guidelines for the treatment of severe aplastic anemia. Working Party on Severe Aplastic Anemia (WPSAA) of the European Group of Bone Marrow Transplantation (EBMT). Haematologica 1994;79:438444.

17 Camitta BM: What is the definition of cure for aplastic anemia? Acta Haematol 2000; 103:16-18. 